\title{
Electrospray Mass Spectrometry: A Study on Some Aqueous Solutions of Metal Salts*
}

\author{
Z. L. Cheng ${ }^{\dagger}$, K. W. M. Siu, R. Guevremont, and S. S. Berman \\ Institute for Environmental Chemistry, National Research Council of Canada, Ottawa, Ontario, Canada
}

Aqueous metal salt solutions were used as models to probe the origin of the species observed in the electrospray mass spectrum. A qualitative or semiquantitative correlation among different species was observed between electrospray responses and calculated equilibrium aqueous solution concentrations. Quantitative correlations were obtained, however, when ions that were identical in charge and similar in type were selected for comparison. In these experiments the ions experienced very similar electrospray-related processes and their effects on the responses were canceled in a comparison of these ions. Consequently, the relative abundances of these ions in the electrospray mass spectrum closely matched the calculated relative abundances in aqueous solution. Our results suggest that the basic principle that determines ionic distribution in the electrospray mass spectrum in aqueous solution chemistry. (J Am Soc Mass Spectrom 1992, 3, 281-288)

$\mathrm{A}$ lthough electrospray mass spectrometry was invented in the late 1960s [1], it was considered at that time to be more a curiosity than an analytical tool. The transformation came about in the early 1980s, after Yamashita and Fenn [2] had proved the analytical potentials of electrospray mass spectrometry. The quantum leap in electrospray research took place a few years later after Fenn and co-workers [3] had convincingly demonstrated the technique's unrivaled capabilities in determining the molecular mass of biopolymers via the formation of multiply charged ions. This aspect alone has made electrospray mass spectrometry arguably the premier technique for molecular mass determination of proteins and other biomacromolecules.

As often occurs with other rapidly advancing techniques, our understanding of the principles behind electrospray mass spectrometry has not kept pace with the rapid expansion in applications. Most practitioners believe that the ions measured are preformed in solution and electrospray merely transfers them from the solution to the gas phase [4-7]. (The transfer mechanism is poorly understood and is an area of some controversy $[6,8-10]$.) Our interest in electro-

\footnotetext{
INRCC 32952. Parts of this study were presented during the 7th Montreux Symposium on Liquid Chromatography/Mass Spectrometry, October 31-November 2, 1990, Montreux, Switzerland.

tOn leave from China National Oceanic Data Centre, Tianjin, China.

Address reprint requests to $K . W . M$. Siu, Institute for Environmental Chemistry, National Research Council of Canada, Ottawa, Ontario, Canada K1A OR9.
}

spray mass spectrometry has lain in smaller ions [11], but we were struck by the relative degree of complexity (i.e., information) of the spectra exhibited by some multiply charged ions [3]. One question that we asked ourselves was whether there was any correlation between electrospray mass spectrum of an analyte and its solution chemistry, and, if so, how they were related.

To answer those questions we decided to measure the electrospray mass spectra of several wellcharacterized proteins under controlled conditions and attempt to correlate the spectral distribution to known solution chemistry of the proteins. We were able to account for the well-known bell-shaped distribution of multiply charged protein ions by means of aqueous solution equilibria of protonated protein species [12]. We were also able to follow the mass spectral shift of cytochrome $c$ induced by thermal denaturation by means of this aqueous solution equilibrium model [13].

Proteins, however, are not ideal candidates in a study where quantitative correlations are examined. Acid dissociation constants of protonated protein species are scarce and the conformation of thesc species in aqueous solution remains poorly understood. We have decided that aqueous solutions of metal salts are much better probes for the question that we posed. First, metal ions produce readily interpretable electrospray mass spectra. Second, the aqueous solution chemistry of metal salts is well characterized and reliable formation constants of a large number of metal salt species are available [14]. 
In this article, we are reporting the electrospray mass spectra of a few aqueous metal salt solutions and are examining the degree of correlation between electrospray mass spectra and the distribution of preformed ions in aqueous solutions.

\section{Experimental}

\section{Instrumentation}

Experiments were performed on a SCIEX TAGA, Model 6000E triple quadrupole mass spectrometer, which has an upper mass limit of $m / z \sim 1400$. For electrospray, the corona discharge assembly was removed and replaced with a laboratory-built electrospray source. The spray probe was fabricated from a 3-cm-long, 33-gauge stainless steel tube (Hamilton, $-100 \mu \mathrm{m}$ ID) that had been attached to a length of $1 / 16^{\prime \prime}$ ID stainless steel tube (typically used in gas chromatography) with epoxy glue. The optimum probe tip position was established from time to time but was generally found to be about $1-2 \mathrm{~cm}$ from the interface plate with the spray off-axis from the orifice. Solutions of metal salts were continuously infused into the spray probe by means of a syringe pump (Harvard Apparatus, Model 22) typically at a rate of $20 \mu \mathrm{L} / \mathrm{min}$. Spraying was achieved at room temperature via biasing the electrospray probe to a typical voltage of $3-3.5 \mathrm{kV}$ by using a high voltage power supply (Tennelec, Model TC950) in series with a $\mathbf{5 0}$ $\mathrm{M} \Omega$ current-limiting resistor. The electrospray current was monitored by a laboratory-made microammeter that could be floated above ground; typical values ranged between 0.1 and $0.2 \mu \mathrm{A}$. Electrical isolation of the probe was achieved by means of fused silica and PEEK (polyetheretherketone, Upchurch) connection tubing.

The lens and quadrupole voltages were optimized for electrospray. Typically, two conditions were employed; one for optimized sensitivity and resolution ("regular" condition) and the other for minimal collision energy in the lens region ("mild" condition). To achieve the two different conditions the magnitude of the dc offset voltage difference between the orifice plate and the radiofrequency-only quadrupole lens was varied. For optimal ion transmission and resolution a typical voltage difference was about 5 to $10 \mathrm{~V}$; for minimal collision energy, the typical voltage difference was $0 \mathrm{~V}$. Mass spectra were acquired with a measurement time of $50 \mathrm{~ms} / \mathrm{step}$ (typically a step was either 0.1 or 0.3 mass to charge ratio). The quadrupole mass filter was typically operated at unit mass resolution. When deemed necessary this was improved to obtain an accurate isotope profile of multiply charged metal ions.

\section{Reagents}

Metal salts were commercially available (Aldrich, Sigma, and Anachemia). All solutions were $100 \%$ aqueous prepared by dissolving the metal salts in deionized distilled water. Typical concentrations were in the 1 to $3 \mathrm{mM}$ range. No acids and bases were added unless explicitly stated. Organic solvents were deliberately excluded for simplicity (effects of organic solvents on the equilibria of metal salt species are little known), although their addition generally results in enhanced sensitivity.

\section{Mass-dependent Discrimination Measurement}

To be able to compare responses from different regions of a given electrospray mass spectrum, the mass-dependent transmission efficiency of the mass spectrometric system had to be estimated. This was performed by means of the electrospray of a $1.13 \mu \mathrm{M}$ solution of a mixture of seven tetraalkylammonium bromide compounds (from tetramethyl- to tetraheptyl-) in $90 / 10$ water/methanol. The chemically and structurally similar surface active tetraalkylammonium ions are the predominant cations present in these solutions. We made the assumption that the difference in their mass spectral responses would be a reasonable estimate of the difference in mass transmission efficiencies. Of course, this required that the variation in electrospray efficiencies (e.g., due to the variation of free energies of hydration) among the tetraalkylammonium ions be relatively minor in comparison to the mass-dependent transmission function.

Figure 1 shows the results obtained under several typical resolution conditions. These results are very similar to a previous measurement by means of atmospheric pressure chemical ionization [15]. This similarity appears to support our approach. We expect that if the approach used here introduced a bias in the estimation of the mass-dependent transmission function, it would be on the side of underestimation. In other words, the potential error lay in underestimating the magnitude of the discriminating effect on higher mass ions.

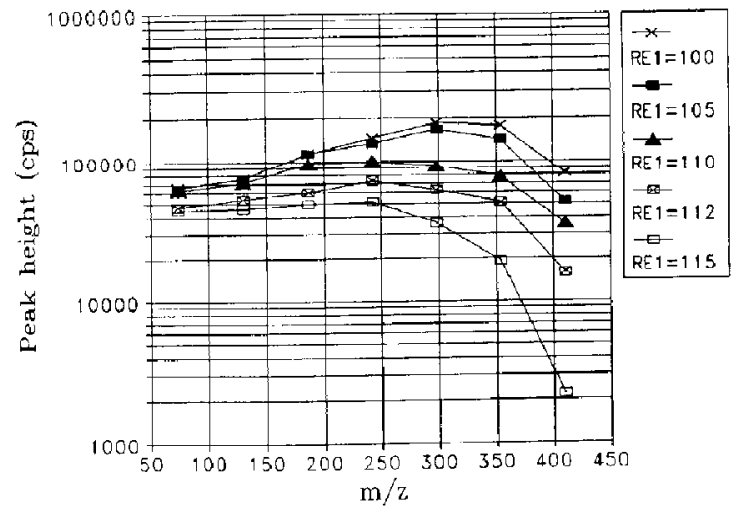

Figure 1. Mass-dependent transmission efficiency under different resolution parameters. (RE1): Resolution decreases with decreasing value of RE1; a value of 115 yielded unit mass or better resolution up to $m / z 450$. 


\section{Equilibrium Calculations}

Equilibrium concentrations of metal salt species in water were calculated through an iterative process with successive approximation via a FORTRAN program, COMICS [16], which was run on an IBM PCcompatible microcomputer. This program required input of formation constants of species that were under consideration. The formation constants used had been scrutinized and compiled by Smith and Martell [14]. Activity coefficients for all ions were assumed to be unity.

\section{Results and Discussion}

Mass spectra of the alkali metals have been available since the early phases of electrospray [2], yet those of the alkaline earth and transition metals were reported only in the last couple of years [17-21]. The reason for this delay may be twofold: Sensitive and selective analytical techniques existed for metal ions while next to none existed for biomacroions; further, it had been believed that desorption of transition metal ions from aqueous solutions was difficult or impossible [22].

Douglas [17] was the first to investigate the possibility of examining metal ions, including transition metal ions, by electrospray. Kebarle and co-workers [18-21] reported investigations on generating gasphase ions of alkaline earth and transition metals by electrospray and their gas-phase ion chemistry. These studies leave little doubt that gas-phase metal-containing ions may be produced in the electrospray process under appropriate experimental conditions.

As previously mentioned, our interests in metal ions lay in their relatively well-characterized solution chemistry; our prime objective was to employ metal salt solutions as probes to investigate the relationship between the electrospray mass spectrum and solution chemistry. To have as simple and as well-characterized a system as possible, we had opted, in this first round of study, to prepare our samples by simply dissolving known quantities of metal salts in water and avoiding the addition of any acids, bases, or organic solvents.

Electrospray mass spectra of 1-3 mM aqueous solutions of some $\mathbf{2 0}$ metal salts, mostly metal halides, have been recorded to date. Results of a few typical salts will be shown here. Figure 2 shows the electrospray mass spectrum of cadmium (II) iodide (2 $\mathrm{mM}$ aqueous solution) under the mild condition. The predominant ions observed were $\mathrm{Cd}\left(\mathrm{H}_{2} \mathrm{O}\right)_{n}^{2+}$ (Figure 2a) and $\mathrm{CdI}\left(\mathrm{H}_{2} \mathrm{O}\right)_{n}^{+}$(Figure 2b). A universal feature in the electrospray mass spectra of aqueous metal salt solutions is the abundance of hydrated clusters. Under the mild condition, it is typical to observe $n$ from about 6 to about 13 for doubly charged ions, and $n$ from about 2 to about 4 for singly charged ions. Cluster identification is made easy because of the metal isotopic pattern and the separation between adjacent hydrated clusters. For example, the clusters

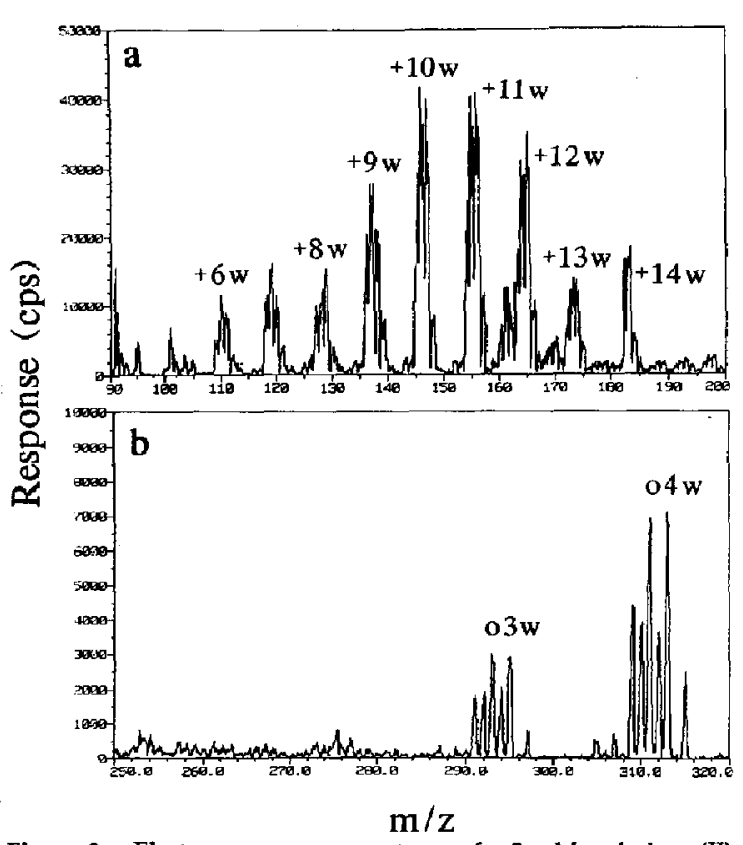

Figure 2. Electrospray mass spectrum of a $2 \mathrm{mM}$ cadmium (II) iodide solution in water, mild lens condition: (a),$+ \mathrm{Cd}\left(\mathrm{H}_{2} \mathrm{O}\right)_{n}^{2+}$ clusters; (b) o, $\mathrm{CdI}\left(\mathrm{H}_{2} \mathrm{O}\right)_{n}^{+}$clusters. Species identification: $10 \mathrm{w}$ means $\left(\mathrm{H}_{2} \mathrm{O}\right)_{10}$.

shown in Figure 2 are clearly cadmium-containing because of their unmistakable cadmium isotopic pattern; the clusters in Figure 2a are doubly charged cadmitum ions because the peaks originating from ${ }^{112} \mathrm{Cd}$ and from ${ }^{114} \mathrm{Cd}$ are separated by one mass-tocharge ratio unit (this is more apparent in Figure $7 a$ ), and the hydrated clusters are distributed nine massto-charge ratio units apart; those in Figure $2 b$ are singly charged because the peaks originating from ${ }^{112} \mathrm{Cd}$ and from ${ }^{114} \mathrm{Cd}$ are separated here by two massto-charge ratio units, and the hydrated clusters are now distributed 18 mass-to-charge ratio units apart.

The spectrum for copper (II) sulphate ( $2 \mathrm{mM}$ aqueous solution, mild condition) is shown in Figure 3 . The predominant series of clusters was due to $\mathrm{Cu}\left(\mathrm{H}_{2} \mathrm{O}\right)_{n}^{2+}$ with $n$ equals 7 to 13 . Once again, the isotopic pattern of copper is unmistakable. The doubly charged assignment is based on the fact that peaks arising from ${ }^{63} \mathrm{Cu}$ and ${ }^{65} \mathrm{Cu}$ are separated by one mass-to-charge ratio unit and the cluster ions are nine mass-to-charge ratio units apart. The minor coppercontaining, singly charged series is due to $\mathrm{Cu}(\mathrm{OH})\left(\mathrm{H}_{2} \mathrm{O}\right)_{n}^{+}$with $n$ being 1 to 4 . Unlike cadmium (II) iodide, copper (II) sulphate does not (cannot) yield $\mathrm{MX}\left(\mathrm{H}_{2} \mathrm{O}\right)_{n}^{+}$ions. Another example that produces singly charged metal/anion complexes is zinc (II) iodide. Figure $4 b$ illustrates this and shows a mass spectral window in which four $\mathrm{ZnI}\left(\mathrm{H}_{2} \mathrm{O}\right)_{n}^{+}$clusters with $n=1$ to 4 are shown ( $2 \mathrm{mM}$ aqueous solution, regular resolution condition).

For some metal salt solutions the only observable 


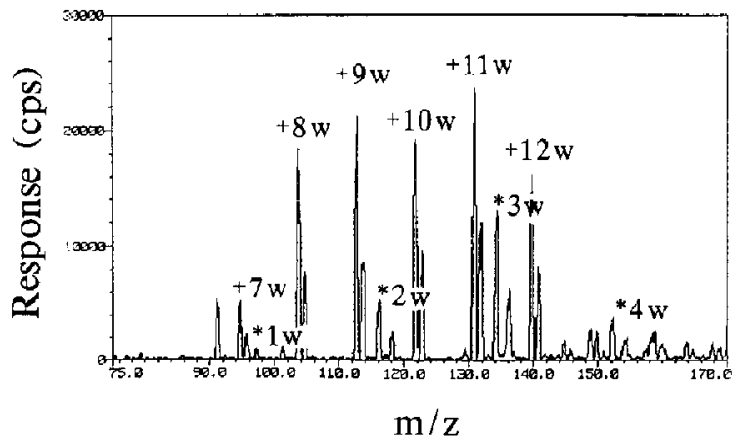

Figure 3. Electrospray mass spectrum of a $2 \mathrm{mM}$ copper (II) sulphate solution, mild lens condition:,$+ \mathrm{Cu}\left(\mathrm{H}_{2} \mathrm{O}\right)_{m}^{2+}$ clusters; *, $\mathrm{Cu}(\mathrm{OH})\left(\mathrm{H}_{2} \mathrm{O}\right)_{n}^{+}$clusters. Species identification: $10 \mathrm{w}$ means $\left(\mathrm{H}_{2} \mathrm{O}\right)_{10}$ -

series of clusters was due to $\mathrm{MOH}\left(\mathrm{H}_{2} \mathrm{O}\right)_{n}^{+}$, e.g., tin (II) chloride ( $2 \mathrm{mM}$, Figure 5) and mercury (II) nitrate (2 $\mathrm{mM}$, Figure 6). In these two figures the upper spectra are shown in semilogarithmic format such that both large and small peaks are visible simultaneously; the lower spectra are portions of the upper spectra portrayed in conventional mass spectrometric format. It should be pointed out that $\mathrm{Sn}(\mathrm{OH})\left(\mathrm{H}_{2} \mathrm{O}\right)_{n}^{+}$is isobaric with $\mathrm{SnCl}\left(\mathrm{H}_{2} \mathrm{O}\right)_{n-1}^{+}$; the assignment of $\mathrm{Sn}(\mathrm{OH})\left(\mathrm{H}_{2} \mathrm{O}\right)_{n}^{+}$in Figure 5 was based on the observation of $\mathrm{Sn}(\mathrm{OH})^{+}$(i.e., $n=0$ ) and the lack of observable chlorine isotopic influence in Figure $5 \mathrm{~b}$. How-

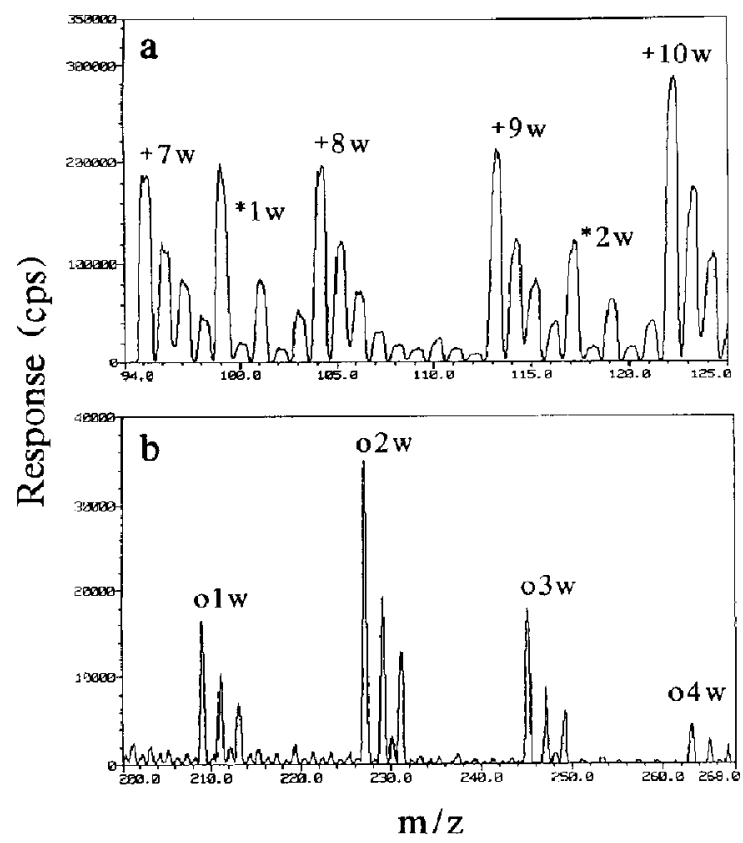

Figure 4. Electrospray mass spectrum of a $2 \mathrm{mM}$ zinc (II) iodide aqueous solution, regular lens condition: (a) + , $\mathrm{Zn}\left(\mathrm{H}_{2} \mathrm{O}\right)_{n}^{2+}$ clusters; ${ }^{+}, \mathrm{Zn}(\mathrm{OH})\left(\mathrm{H}_{2} \mathrm{O}\right)_{n}^{+}$clusters; (b) 0 , $\mathrm{Znl}\left(\mathrm{H}_{2} \mathrm{O}\right)_{n}^{+}$clusters. Species identification: $10 \mathrm{w}$ means $\left(\mathrm{H}_{2} \mathrm{O}\right)_{10}$
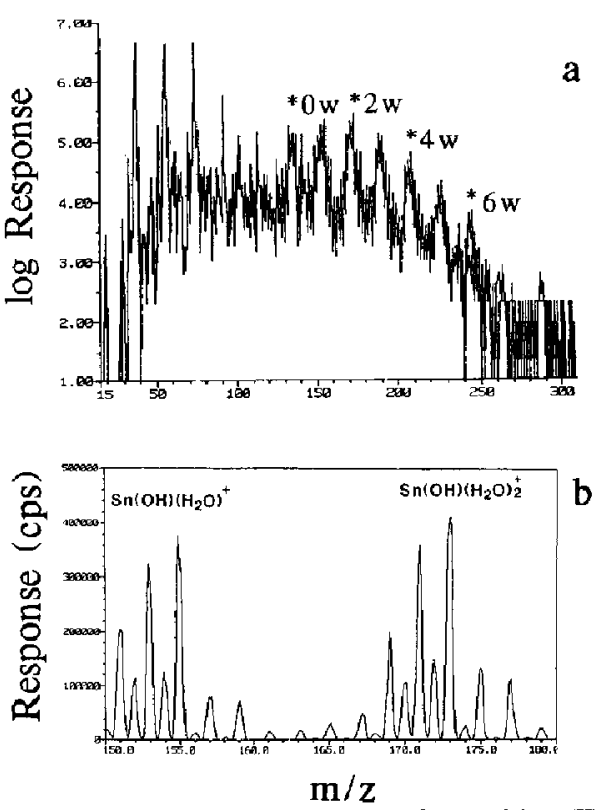

Figure 5. Electrospray mass spectrum of a $2 \mathrm{mM}$ tin(II) chloride solution in water, regular lens condition: (a) response in logarithmic format; ${ }^{*}, \operatorname{Sn}(\mathrm{OH})\left(\mathrm{H}_{2} \mathrm{O}\right)_{n}^{+}$clusters; number before $w$ equals $n$; (b) expanded portion of (a) in normal format showing two clusters, $n=1$ and $n=2$.
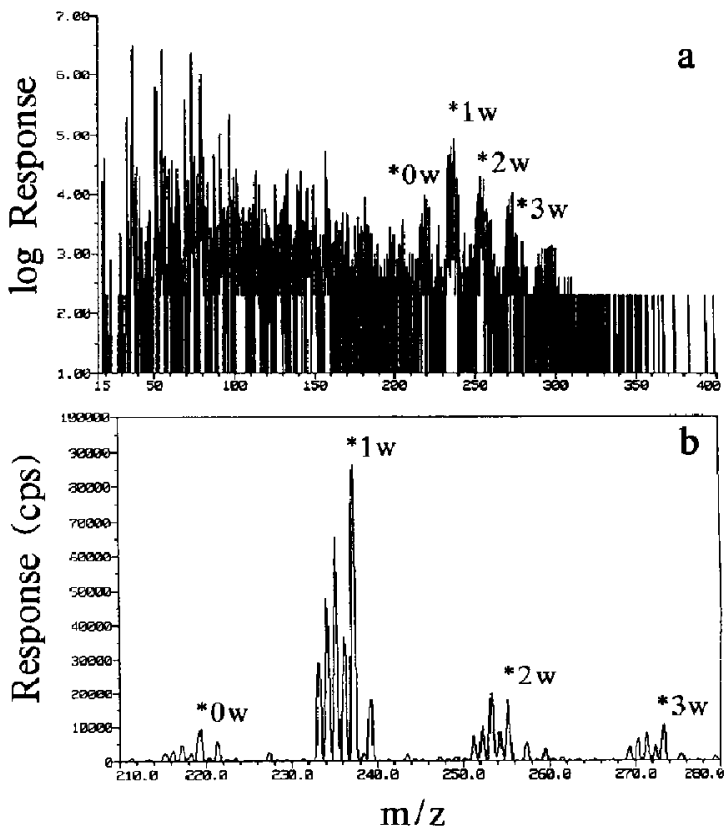

Figure 6. Electrospray mass spectrum of a $2 \mathrm{mM}$ mercury (II) nitrate solution in water, regular lens condition: (a) response in logarithmic format; ${ }^{*}, \mathrm{Hg}(\mathrm{OH})\left(\mathrm{H}_{2} \mathrm{O}\right)_{n}^{2+}$ clusters; (b) expanded portion of (a) in normal format showing four clusters, $n=0$, $n=1, n=2, n=3$. 
ever, it is possible that $\mathrm{SnCl}\left(\mathrm{H}_{2} \mathrm{O}\right)_{n-1}^{+}$could be present as a minor constituent.

The degree of hydration that we witnessed in our experiments was typically higher than that of organic ions such as tetraalkyl (butyl to hepta) ammonium ions under identical lens (hence cluster breaking) potentials. We attributed this to the much higher charge densities of metal-containing ions primarily because of their smaller sizes. The observation that $\mathrm{M}^{2+}$ ions were far more heavily hydrated than $\mathrm{MX}^{+}$ions (where $M$ and $X$ represent any divalent metal ion and halide ion, respectively) paralleled a previous observation made on a series of aliphatic dicarboxylic acids [11].

The metal-containing ions that we have seen in the electrospray mass spectra are in accord with the species present in solution. Formation constants of a large number of metal anion complexes are known and have been critically evaluated [14]. We were able to calculate equilibrium concentrations of metal complexes in aqueous solution by entering these constants, the total metal and anion concentrations as well as $\mathrm{pH}$ into the Fortran program, COMICS. The results for the five metal salt solutions that are being considered here are shown in Table 1 . It is tempting to over interpret the comparison between spectral abundances and solution concentrations among the different metal salts and complexes. Two major sources of problems exist in the comparison of abundances of ions in the electrospray mass spectrum and the abundances of ions (especially oxides and hydroxides) in aqueous solution. The first is related to the electrospray process itself. With regard to the solution chemistry there are several potential sources of error in the calculated concentrations of species in solution. For example, the calculated concentration of $\mathrm{Cd}(\mathrm{OH})^{+}$ in Table 1 is clearly wrong if the only component added to the aqueous solution was $\mathrm{CdI}_{2}$ to yield a final solution $\mathrm{pH}$ of 5.2 (i.e., the $\mathrm{pH}$ must have been lowered, in part, due to the hydrolysis of metal ions). In addition, it also must be recognized that an error might exist in the measurement of $\mathrm{pH}$ (e.g., due to liquid junction potential) in dilute solutions. The presence of very low concentrations of organic compounds $\left(10^{-5} \mathrm{M}\right)$ affects $\mathrm{pH}$ and the accuracy of its measurement in very dilute aqueous solutions. From the point of view of the electrospray process, the comparison between abundances of inns in the electrospray mass spectrum and the abundances of ions in aqueous solution will also be difficult if the electrospray ion desorption process, or gas-phase chemistry, is species-dependent. It must be borne in mind that ions different in nature (i.e., charge, type, or kind) are likely to have different desorption efficiencies in electrospray, thus making quantitative comparisons among these ions difficult. The only time when a quantitative comparison of ion abundances in a given mass spectrum is possible is the one in which ions identical in charge and very similar in nature are involved, as will be illustrated below.

Comparing the data in Table 1 and the electrospray mass spectra, we can observe a qualitative agreement between the species expected in solution and the species observed in the spectrum. Let us set aside the doubly charged species for the time being and concentrate only on the singly charged $\mathrm{MX}^{+}$and $\mathrm{M}(\mathrm{OH})^{+}$ species. For cadmium (II) iodide, the solution concentration of $\mathrm{CdI}^{+}$was much higher than that of $\mathrm{Cd}(\mathrm{OH})^{+}$; we saw substantial $\mathrm{CdI}\left(\mathrm{H}_{2} \mathrm{O}\right)_{n}^{+}$response and none from $\mathrm{Cd}(\mathrm{OH})\left(\mathrm{H}_{2} \mathrm{O}\right)_{n}^{+}$. The electrospray sensitivity for zinc (II) iodide was very high and both $\mathrm{Znl}\left(\mathrm{H}_{2} \mathrm{O}\right)_{n}^{+}$and $\mathrm{Zn}(\mathrm{OH})_{n}^{+}$were observed even though their calculated solution concentrations were relatively low. The predominant singly charged tin (II) species in solution was calculated to be $\mathrm{Sn}(\mathrm{OH})^{+}$and the prime observable series of ions were $\operatorname{Sn}(\mathrm{OH})$ $\left(\mathrm{H}_{2} \mathrm{O}\right)_{n}^{+}$. The solution concentration of $\mathrm{Hg}(\mathrm{OH})^{+}$was calculated to be much higher than that of $\mathrm{HgNO}_{3}^{+}$; only $\mathrm{Hg}(\mathrm{OH})\left(\mathrm{H}_{2} \mathrm{O}\right)_{n}^{+}$ions were observed. For the doubly charged ions, it was generally observed that their responses were lower (relative to those of the singly charged ions) than expected from their solution concentrations. This apparent discrepancy in the evaporation efficiencies of singly and doubly charged ions has also been observed in a previous study involving organic ions with multicarboxylate and/or multisulphonate groups [11]. Here, as previously, we speculate that the apparent higher evaporation efficiencies of singly (versus doubly) charged ions are due to the lower free energies of hydration of these ions [23].

In addition, it was observed that for several metal salt solutions in which $\mathrm{M}(\mathrm{OH})^{+}$is not expected to be abundant in solution, the $\mathrm{M}(\mathrm{OH})\left(\mathrm{H}_{2} \mathrm{O}\right)_{n}^{+}$response is relatively too high. For these solutions, the relative responses of $\mathrm{M}(\mathrm{OH})\left(\mathrm{H}_{2} \mathrm{O}\right)_{n}^{+}$versus $\mathrm{MX}\left(\mathrm{H}_{2} \mathrm{O}\right)_{n}^{+}$and $\mathrm{M}\left(\mathrm{H}_{2} \mathrm{O}\right)_{n}^{2+}$ increase with the ion energy imposed in

Table 1. Calculated concentrations of predominant charged species in solution ${ }^{\text {a }}$

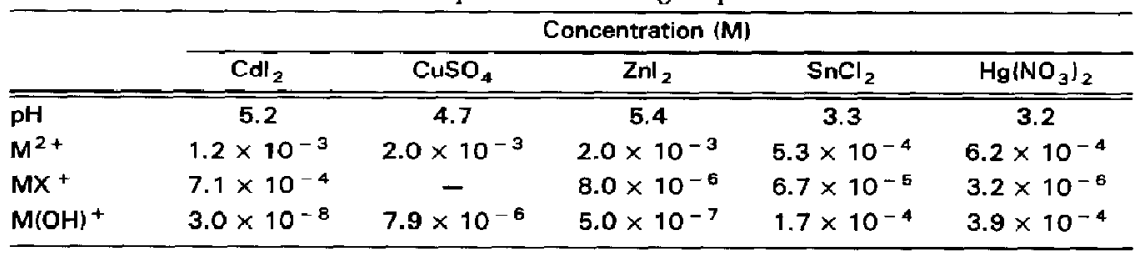

Metal salt concentrations were all $2 \mathrm{mM}$; activity coefficients $=1$. 
the lens region (proportional to the difference between the bias voltage on the orifice plate and that on the quadrupole lens). One metal salt that exhibits this trend is cadmium (II) iodide. Figure 7 shows an expanded portion of the mass spectrum of a $2 \mathrm{mM}$ cadmium iodide solution recorded under the regular condition (with a lens voltage difference of $8 \mathrm{~V}$ ). In Figure 7 , the presence of $\mathrm{Cd}(\mathrm{OH})^{+}$(which partially overlaps with $\left.\mathrm{Cd}\left(\mathrm{H}_{2} \mathrm{O}\right)_{8}^{2+}\right)$ is quite apparent. Thus, $\mathrm{Cd}(\mathrm{OH})\left(\mathrm{H}_{2} \mathrm{O}\right)_{n}^{+}$was observed to increase in response (both relative and absolute) from nondetectable to significant when the lens voltage difference was increased from 0 to $8 \mathrm{~V}$. For some metal salts, the $\mathrm{M}(\mathrm{OH})\left(\mathrm{H}_{2} \mathrm{O}\right)_{n}^{+}$response does not vanish completely even when the lens voltage difference is at zero, for instance, copper salts (e.g., Figure 3). These results are in accord with the reports of Kebarle and coworkers [18-21] in which significant gas-phase conversions of $\mathrm{M}(\mathrm{OH})\left(\mathrm{H}_{2} \mathrm{O}\right)_{n}^{+}$from $\mathrm{M}\left(\mathrm{H}_{2} \mathrm{O}\right)_{m}^{2+}$ (where $m>n$ ) were discussed. The presence of solventderived metal oxide species is an interesting subject that we plan to address in more detail in a later report. Suffice it to say here that the $\mathrm{M}(\mathrm{OH})\left(\mathrm{H}_{2} \mathrm{O}\right)_{n}^{+}$ responses for some metal salt solutions appeared larger than those that can be expected from their calculated equilibrium concentrations.

So far we have seen a qualitative or an arguably
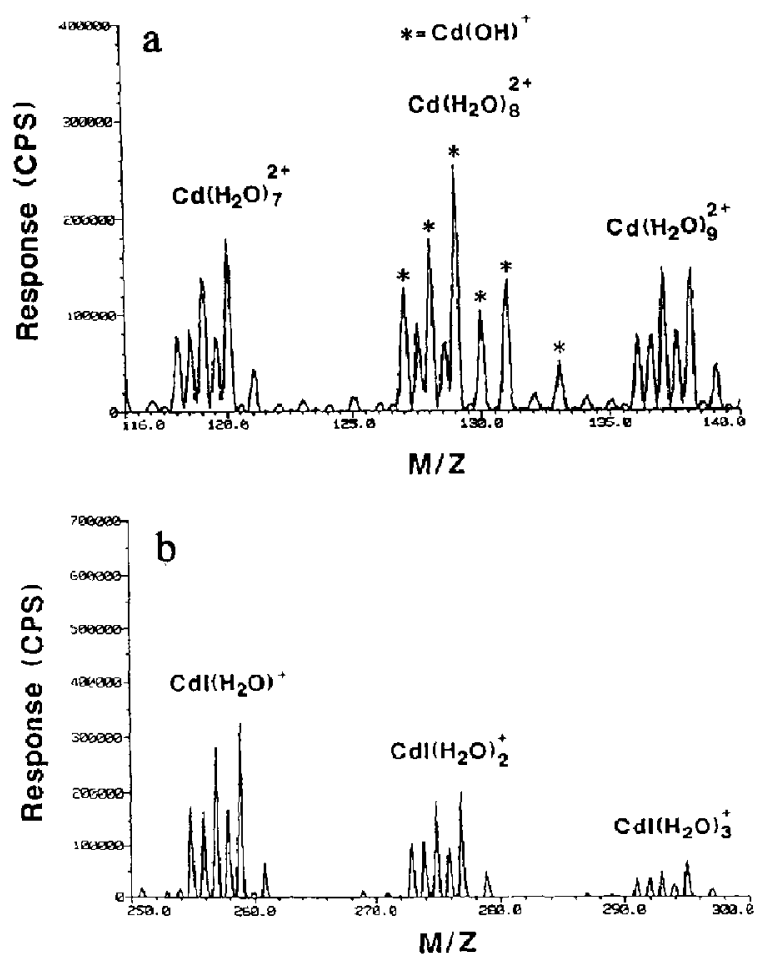

Figure 7. Electrospray mass spectrum of a $2 \mathrm{mM}$ cadmium (II) iodide solution in water, regular lens condition: *, denotes contribution from $\mathrm{Cd}(\mathrm{OH})^{+}$. semiquantitative resemblance between calculated species equilibrium solution concentrations and the electrospray responses of those species. The reason for this relatively poor inter-species correlation is apparently due to the different processes and desorption efficiencies experienced by these different species. To investigate the relationship between the electrospray mass spectrum and solution chemistry, the effects of these species-dependent and evaporation-related processes would have to be canceled in any quantitative comparisons. This can be achieved in an experiment wherein species that are identical in charge and similar in kind are evaluated. Two such experiments were performed. The first one involved a series of solutions containing varying ratios of cadmium (II) iodide to cadmium (II) chloride; the second involved solutions of silver nitrate containing different concentrations of ammonia.

In the cadmium sait experiment a series of aqueous solutions containing a fixed cadmium halide concentration ( $2 \mathrm{mM}$ in cadmium and $4 \mathrm{mM}$ in chloride plus iodide) was analyzed by electrospray and their $\mathrm{CdCl}\left(\mathrm{H}_{2} \mathrm{O}\right)_{n}^{+}$and $\mathrm{CdI}\left(\mathrm{H}_{2} \mathrm{O}\right)_{n}^{+}$responses compared. In this study it is reasonable to assume that the electrospray processes experienced by $\mathrm{CdCl}^{+}$and $\mathrm{CdI}^{+}$were very similar, and a comparison of the two species would allow the cancellation of evaporation-related contributions and hence reveal any partially obscure fundamental trend such as one that might be imposed by solution chemistry. Figure 8 illustrates a comparison between the calculated $\mathrm{CdX}^{+}(\mathrm{X}=\mathrm{Cl}$ or $\mathrm{I})$ concentrations (upper plot) and the $\mathrm{CdX}^{+}$responses (sum of all hydrated clusters) (lower plot) as a function of the total chloride concentrations in solution; the total chloride plus iodide concentration was kept constant at $4 \mathrm{mM}$ while the total cadmium concentration was maintained at $2 \mathrm{mM}$. The responses shown have previously been corrected for mass-dependent discrimination. Good quantitative agreement between the plots is evident. The $\mathrm{CdX}^{+}$response follows the same trend as the calculated $\mathrm{CdX}{ }^{+}$solution concentration. $\mathrm{CdCl}^{+}$concentration and $\mathrm{CdCl}^{+}$response increase while $\mathrm{CdI}^{+}$concentration and $\mathrm{CdI}^{+}$response decrease as the ratio of total chloride to total iodide concentration is raised; the rates of change between solution concentrations and mass spectral responses are comparable. The total chloride concentrations where calculated $\mathrm{CdX}^{+}$concentrations and measured $\mathrm{CdX}^{+}$electrospray responses are identical are estimated to be 2.6 and $2.3 \mathrm{mM}$, respectively. These numbers are judged identical given the uncertainties in measurement and in the relevant formation constants.

In the second experiment a series of solutions containing a fixed silver nitrate concentration at $2 \mathrm{mM}$ but a varying concentration of ammonia from 0.1 to 20 $\mathrm{mM}$ were prepared and analyzed sequentially. (This was the only experiment in which materials other than the metal salts and water were employed.) It is 


$$
\begin{gathered}
\text { Calculated }[\mathrm{CdX}+] \text { vs }[\mathrm{Cl}-] \text { added } \\
{[\mathrm{Cl}-]+[1-]=\underset{\mid \mathrm{CaCl}+1}{4 \mathrm{mM}}}
\end{gathered}
$$

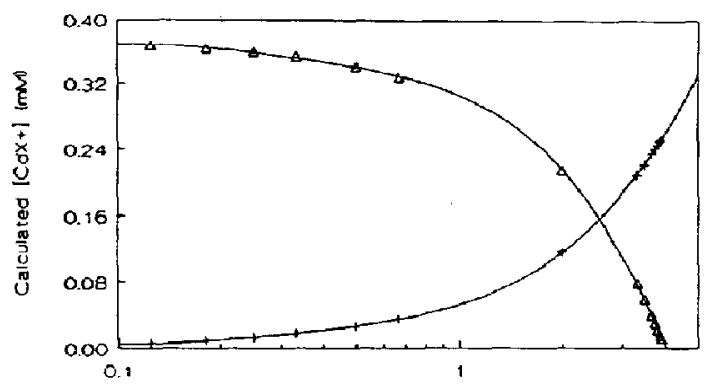

$\mathrm{ICl}-1$ added $\mathrm{cmM}$

$$
\begin{gathered}
{[\mathrm{CdX}+] \text { response vs }[\mathrm{Cl}-] \text { added }} \\
{[\mathrm{Cl}]+[1-1=\underset{4 \mathrm{Ca}+1}{+} \mathrm{mM}}
\end{gathered}
$$

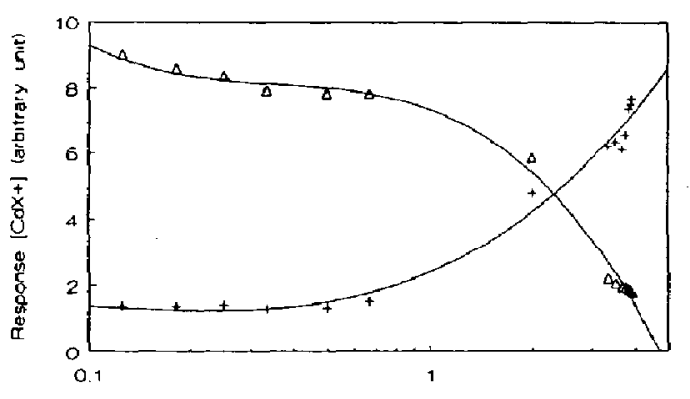

[Cl-1 added (mM!)

Figure 8. Calculated concentrations of $\mathrm{CdX}^{+}$in solution and responses of $\mathrm{CdX}^{+}$(sum of all hydrate clusters) at different total chloride/total iodide ratios:,$+ \mathrm{CdCl}^{+}$concentration or $\mathrm{CdCl}^{+}$ response; $\triangle, \mathrm{CdI}^{+}$concentration or $\mathrm{CdI}^{+}$response. Solutions were prepared by the dissolution of appropriate amounts of cadmium(II) chloride and cadmium(II) iodide in water; the total halide concentrations were constant at $4 \mathrm{mM}$.

well-known that silver complexes with ammonia to form $\mathrm{Ag}\left(\mathrm{NH}_{3}\right)^{+}$and $\Lambda \mathrm{g}\left(\mathrm{NH}_{3}\right)_{2}^{+}$in solution. In Figure 9 the relative responses of the two singly charged adduct ions (sum of all hydrated clusters) and their relative equilibrium concentrations in solution are plotted versus the aqueous ammonia concentrations. A difference of $3 \mathrm{~V}$ in lens voltages was used for this experiment (to ensure adequate sensitivity for low ammonia concentration measurements). The degree of collision-induced conversion from $\mathrm{Ag}\left(\mathrm{NH}_{3}\right)_{2}$ $\left(\mathrm{H}_{2} \mathrm{O}\right)_{m}^{+}$to $\mathrm{Ag}\left(\mathrm{NH}_{3}\right)\left(\mathrm{H}_{2} \mathrm{O}\right)_{n}^{+}(m>n)$ in the lens region was measured in a separate experiment in which a 2-mM silver nitrate solution containing $0.18 \mathrm{M}$ ammonia was analyzed. According to equilibrium calculation, the relative concentration between $\mathrm{Ag}\left(\mathrm{NH}_{3}\right)_{2}^{+}$ and $\mathrm{Ag}\left(\mathrm{NH}_{3}\right)^{+}$in this solution was about 1400 to 1 . Consequently, we assumed that any $\mathrm{Ag}\left(\mathrm{NH}_{3}\right)\left(\mathrm{H}_{2} \mathrm{O}\right)_{n}^{+}$

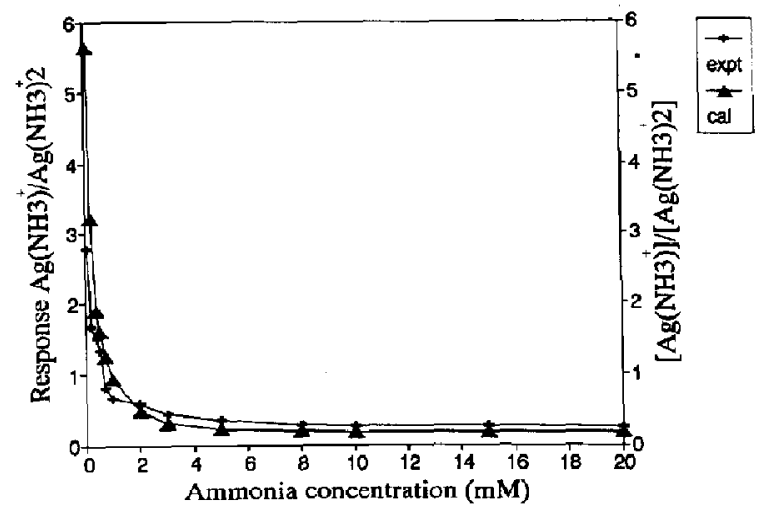

Figure 9. Calculated relative concentrations of $\mathrm{Ag}\left(\mathrm{NH}_{3}\right)^{+}$and $\mathrm{Ag}\left(\mathrm{NH}_{3}\right)_{2}^{+}$in solution and relative responses (sum of all hydrated clusters) of $\mathrm{Ag}\left(\mathrm{NH}_{3}\right)^{+}$and $\mathrm{Ag}\left(\mathrm{NH}_{3}\right)_{2}^{+}$versus ammonia concentration in solution: + , relative response corrected for $15 \%$ gas-phase conversion of $\mathrm{Ag}\left(\mathrm{NH}_{3}\right)_{2}^{+}$to $\mathrm{Ag}\left(\mathrm{NH}_{3}\right)^{+} ; \Delta$, relative concentration.

signal that we saw in the electrospray mass spectrum was due to gas-phase conversion from $\mathrm{Ag}\left(\mathrm{NH}_{3}\right)_{2}\left(\mathrm{H}_{2} \mathrm{O}\right)_{m}^{+}$to $\mathrm{Ag}\left(\mathrm{NH}_{3}\right)\left(\mathrm{H}_{2} \mathrm{O}\right)_{n}^{+}$. As expected, the degree of this conversion increased with increasing voltage difference employed in the lens region. We estimated that, with the present experimental setting of a voltage difference of $3 \mathrm{~V}$, about $15 \%$ of $\mathrm{Ag}\left(\mathrm{NH}_{3}\right)_{2}\left(\mathrm{H}_{2} \mathrm{O}\right)_{m}^{+}$was converted to $\mathrm{Ag}\left(\mathrm{NH}_{3}\right)\left(\mathrm{H}_{2} \mathrm{O}\right)_{n}^{+}$ in the gas phase; this small conversion factor was included in the relative response plot. The agreement between the relative responses and the relative solution concentrations was good.

These two experiments suggest that the fundamental principal governing electrospray mass spectrometry appears to be aqueous solution chemistry. However, since different types of ions may experience drastically different electrospray efficiencies and processes, a quantitative correlation between the electrospray mass spectral responses and the solution concentrations may not be readily observable. Indeed, the correlation among different types of ions is so apparently skewed that only qualitative trends are apparent. That is to say, although solution chemistry dictates the types of ions that appear in the electrospray mass spectrum, other processes may modify the abundances of those ions. As shown above, these desorption-related contributions can be canceled in carefully designed experiments; once this is done, quantitative relationship between species solution concentration and electrospray response is revealed.

\section{References}

1. Dole, M.; Mack, L. L.; Hines, R. L.; Mobley, R. C.; Ferguson, L. D.; Alice, M. B. J. Chem. Phys. 1968, 49, 2240.

2. Yamashita, M.; Fenn, J. B. J. Phys. Chem. 1984, 88, 4451.

3. Mann, M.; Meng, C. K.; Fenn, J. B. Anal. Chem. 1989, 61, 1702. 
4. Iribarne, J. V.; Thomson, B. A. J. Chem. Phys. 1976, 64, 2287.

5. Thomson, B. A.; Iribarne, J. V. J. Chem. Phys. 1979, 71, 4451.

6. Fenn, J. B.; Mann, M.; Meng, C. K.; Wong, S. F.; Whitehouse, C. M. Mass Spectrom. Rev. 1990, 9, 37.

7. Smith, R. D.; Loo, J. A.; Edmonds, C. G.; Barinaga, C. J.; Udseth, H. R. Anal. Chem. 1990, 62, 882.

8. Fenn, J. B. Presented at the 7th Montreux Symposium on Liquid Chromatography/Mass Spectrometry, October 31-November 2, 1990, Montreux, Switzerland.

9. Vestal, M. L. Presented at the 7th Montreux Symposium on I.iquid Chromatrgraphy/Mass Spectrometry, October 31-November 2, 1990, Montreux, Switzerland.

10. Röllgen, F. W.; Bramer-Weger, E.; Bütfering, L. J. Phys. 1987, 48, C6-253.

11. Siu, K. W. M.; Gardner, G. J.; Berman, S. S. Org. Mass Spectrom. 1989, 24, 931.

12. Guevremont, R.; Siu, K. W. M.; Le Blanc, J. C. Y.; Berman, S. S. I. Am. Soc. Mass Spectrom., 1992, 3, 216.

13. Le Blanc, J. C. Y.; Beauchemin, D.; Siu, K. W. M.; Guevre- mont, R.; Berman, S. S. Org. Mass Spectrom., 1991, 26, 831. 14. Smith, R. M.; Martell, A. E. Critical Stability Constants, Vol. 4: Inorganic Complexes; Plenum: New York, 1981, p 135.

15. Sunner, J.; Nicol, G.; Kebarle, P. Anal. Chem. 1988, 60, 1300.

16. Perrin, D. D.; Sayce, 1. G. Talanta 1967, 14, 833.

17. Douglas, D. J. Presented at the Winter Conference on Plasma Spectrochemistry, St. Petersburg, FL, January 1990, Paper IL-11.

18. Blades, A. T.; Jayaweera, P.; Ikonomou, M. G.; Kebarle, P. J. Chem. Phys. 1990, 92, 5900.

19. Jayaweera, P.; Blades, A. T.; Ikonomou, M. G.; Kebarle, P. J. Am. Chem. Soc: 1990, 112, 2452.

20. Blades, A. T.; Jayaweera, P.; Ikonomou, M. G.; Kebarle, P. Int. J. Mass Spectrom. Ion Processes 1990, 701, 325.

21. Blades, A. T.; Jayaweera, P.; Ikonomou, M. G.; Kebarle, P. Int. J. Mass Spectrom. Ion Processes 1990, 102, 251.

22. Iribarne, J. V.; Dziedzic, P. J.; Thomson, B. A. Int. J. Mass Spectrom. Ion Processes 1983, 50, 331.

23. Marcus, Y. Ion Solvation; John Wiley: New York, 1985, p 107. 